\title{
PRODUÇÃO DE DADOS EM CLIMATOLOGIA GEOGRÁFICA: APLICAÇÃO ÀS ESCALAS INFERIORES DO CLIMA
}

\author{
GALVANI, Emerson - egalvani@usp.br \\ Universidade de São Paulo / USP
}

\begin{abstract}
RESUMO: Apresenta-se um relato de estratégias utilizadas para obtenção de dados primários em pesquisas climáticas com destaque para as escalas topo e microclimáticas apontando desafios e possibilidades. Indica-se que é possível pensar em estratégias, metodologicamente, adequadas para monitorar os atributos do clima e responder às perguntas de seu projeto de pesquisa; a falta de recursos financeiros e humanos pode ser contornada com criatividade e parcerias; e a necessidade de conhecer seu objeto de pesquisa por meio de pesquisa bibliográfica e leitura sobre o tema.
\end{abstract}

PALAVRAS-CHAVES: instrumental meteorológico, coletor de nevoeiros, microclima de manguezal, conforto humano

\section{GEOGRAPHIC CLIMATOLOGY DATA PRODUCTION: APPLICATION TO MICROCLIMATE SCALES}

\begin{abstract}
A report is presented of strategies used to obtain primary data in climate research with emphasis on the top and microclimatic scales indicating challenges and possibilities. It is indicated that possible to think of methodologically appropriate strategies for monitoring climate attributes and answering the questions of your research project; the lack of financial and human resources can be resolved with creativity and partnerships and; the need to know your research object through bibliographic research and reading about your research project.
\end{abstract}

KEYWORDS: meteorological instrumental, fog collector, mangrove microclimate, human comfort.

\section{INTRODUÇÃO E PRIMEIRAS IMPRESSÕES}

Todo pesquisador, em qualquer nível de formação, em algum momento de sua carreira se depara com questões relacionadas à obtenção de dados. Perguntas como "onde obtenho os dados de minha área de estudo?"; "Essa série histórica tem muitas falhas o que fazer?"; "Já enviei dois emails para o instituto responsável e não obtenho retorno o que faço?"; "A estação meteorológica ou posto pluviométrico mais próximo fica a muitos quilômetros da área de estudo, será que tem representação espacial e validade temporal?". No âmbito da Climatologia, e da Climatologia Geográfica, isso não é diferente sendo muito comum a busca incessante por dados em diferentes instituições e agencias reguladoras. Usamos por vezes a expressão "negados meteorológicos" como antônimo de "dados meteorológicos". Isso de fato tem mudado com a Lei de Acesso a Informação (LAI) conforme previsto na Lei No 12.527, de 18 de novembro de $2011^{1}$ que determina em seu Artigo $6^{\circ}$ que "Cabe aos órgãos e entidades do poder público, observadas as normas e procedimentos específicos aplicáveis, assegurar a: I - gestão transparente da informação, propiciando amplo acesso a ela e sua divulgação". Com isso e a força desse instrumento legal o acesso às bases de dados dos agentes públicos ganharam uma nova

\footnotetext{
${ }^{1}$ (Disponível em http://www.planalto.gov.br/ccivil_03/_ato2011-2014/2011/lei/l12527.htm . Acesso em: maio de 2019).

Ano 15 - Edição Especial - XIII Simpósio Brasileiro de Climatologia Geográfica - JUN 2019
} 
dimensão. O Banco de Dados Meteorológicos para Ensino e Pesquisa (BDMEP) ${ }^{2}$ é de fato um sinal de novo momento na produção da informação, assim como os dados pluviométricos e hidrometeológicos administrados pela Agência Nacional de Águas (ANA) por intermédio da plataforma Hidroweb, além de outras bases em escalas estaduais e regionais. Mesmo assim, estamos falando aqui de dados secundários e obtidos em condição padrão conforme preconiza a Organização Meteorológica Mundial (OMM) e adotada pelos Institutos Nacionais de observação meteorológica de superfície, como INMET, CPTEC/INPE, IAC, IAPAR, FEPAGRO, EPAGRI, EPAMIG, SIMERJ, FUNCEME, SIPAM, SIVAM, SUDENE, INEMA/BA e tantos outros órgãos que agora me faltam à memória.

Como devemos proceder quando nosso objeto de estudo expressam condições em que "as diferenças de exposição introduzem grandes contrastes entre as vertentes numa mesma latitude e altitude" (Ribeiro, 1993, p.03). Ou ainda, o microclima é "resultante de condições muito particulares da circulação junto ao solo, no interior de uma formação vegetal ou de um grupamento urbano" (Pedelaborde, 1959). Estamos falando aqui, obviamente, de recortes escalares que envolvem os níveis topo e microclimáticos, respectivamente. Ou seja, àqueles dados da estação meteorológica oficial, no plano, com cobertura de grama, amplo horizonte.... não conseguem expressar, fidedignamente, e essa nova condição indica a necessidade do pesquisador produzir seus próprios dados. É disso que vamos tratar aqui.

\section{AS EXPERIÊNCIAS ACUMULADAS NO TEMPO}

Ao longo dessa vivência, experiência e mais aprendizado, de 16 anos de Universidade de São Paulo atuando junto ao Departamento de Geografia e, especificamente, vinculado ao Laboratório de Climatologia e Biogeografia e uma boa bagagem de orientandos em todos os níveis permitam-me indicar e descrever alguns projetos que se serviram dos pressupostos teóricoepistemológicos-técnicos das escalas inferiores do clima (meso, topo e microclimática). Claro que não há espaço para discutir todos os projetos desenvolvidos nesse período, adota-se como premissa, então àqueles que de alguma maneira fizeram uso de técnicas e tecnologias na produção de dados primários.

\subsection{A COLETA DE NEVOEIROS - PARTE 1}

A tese intitulada "Avaliação do potencial hidrológico dos nevoeiros e da precipitação oculta em ambiente de Floresta Ombrófila Densa Montana na Serra do Mar, Cunha, SP ${ }^{34}$," de autoria do Dr. Francisco Carlos Soriano Arcova

\footnotetext{
${ }^{2}$ As variáveis atmosféricas disponibilizadas para consultas no BDMEP são: precipitação ocorrida nas últimas 24 horas; temperatura do bulbo seco; temperatura do bulbo úmido; temperatura máxima; temperatura mínima; umidade relativa do ar; pressão atmosférica ao nível da estação; insolação; direção e velocidade do vento. Disponível em: http://www.inmet.gov.br/portal/index.php?r=bdmep/bdmep / Acesso em: Maio de 2019

${ }^{3}$ Disponível em: http://www.teses.usp.br/teses/disponiveis/8/8135/tde-03022014-115048/pt-br.php. Acesso em: maio de 2019).

${ }^{4}$ Artigo com os resultados da tese publicados em: ARCOVA, Francisco Carlos Soriano et al. AVALIAÇÃO DA PRECIPITAÇÃO OCULTA NA SERRA DO MAR COM COLETORES PASSIVOS DE NEVOEIRO. Revista Brasileira de Climatologia, [S.I.], v. 25, ago. 2019. ISSN 2237-8642. Disponível em: Ano 15 - Edição Especial - XIII Simpósio Brasileiro de Climatologia Geográfica - JUN 2019
} 
defendida junto ao Programa de Pós-Graduação em Geografia Física da FFLCH/USP em novembro de 2013. Teve como premissa a hipótese de que na área de estudo os nevoeiros apresentam elevado potencial hidrológico, e a precipitação oculta na Floresta Ombrófila Densa Montana é importante processo de entrada de água para as microbacias da região de Cunha, SP. Para responder essa demanda optou-se pela construção e instalação de coletares de nevoeiro conforme preconiza a literatura especializada no estudo do tema. A figura 1 apresenta dois modelos de coletores de nevoeiro utilizados, um plano e outro cilíndrico.

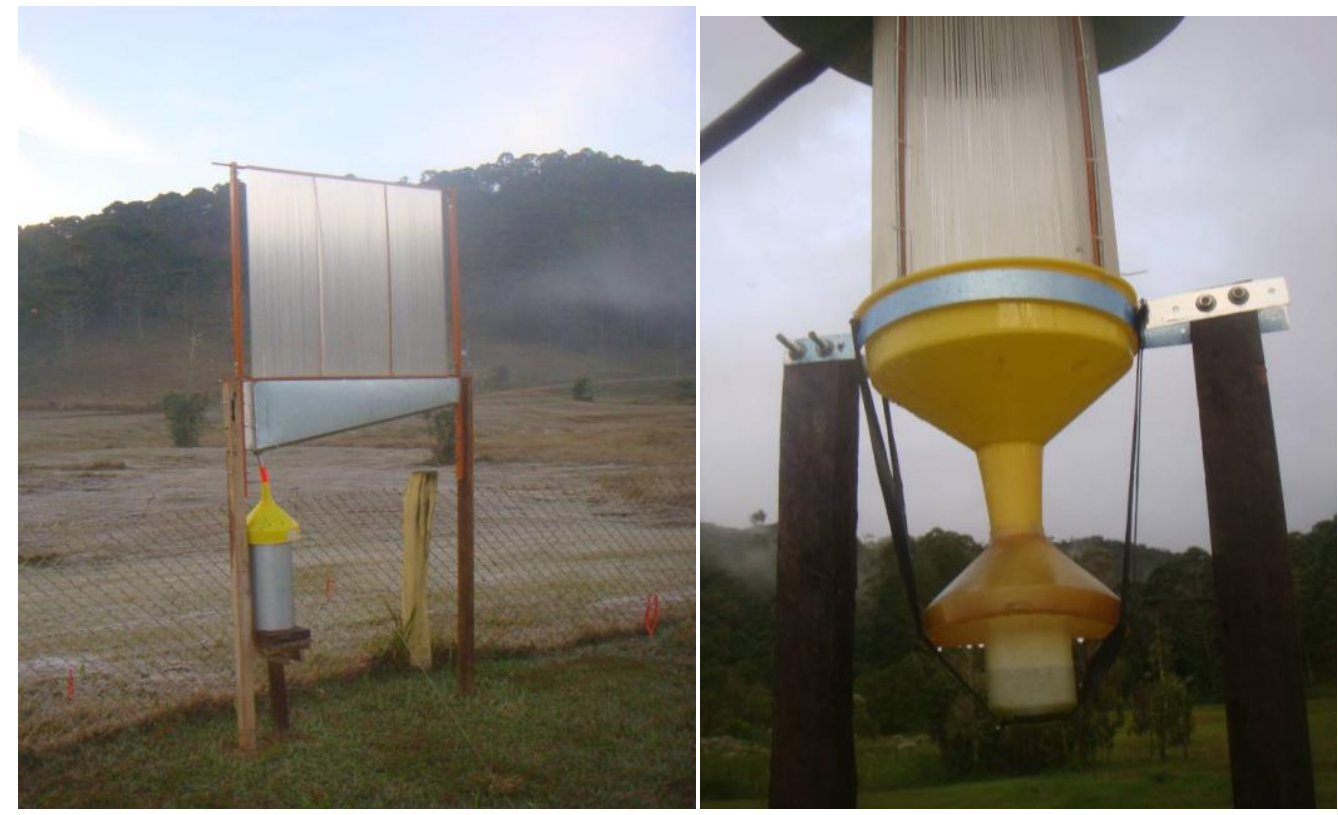

Figura 1 - Vista geral de um coletor plano (esquerda) e cilíndrico com cobertura (direita) de água de nevoeiro instalado no Laboratório de Hidrologia Florestal Walter Emmerich, Parque Estadual Serra do Mar, núcleo Cunha, SP. (Foto: Francisco C. S. Arcova,

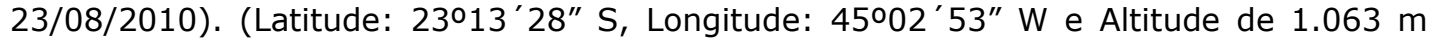
ANMM).

Ao final da tese, dentre as inúmeras contribuições que foram obtidas, especificamente sobre a coleta de nevoeiros evidenciou-se: Com relação ao potencial hidrológico dos nevoeiros na área de estudo, concluiu-se: - houve coleta de água de nevoeiro ao longo das quatro estações do ano, porém os maiores volumes incidiram no outono e inverno; - as taxas de coleta foram reduzidas, com valores médios de $290,5 \mathrm{~mL} \cdot \mathrm{m}^{-2} \cdot \mathrm{d}^{-1}$ para o coletor cilíndrico descoberto; e os escassos volumes de água obtidos resultaram da combinação de ao menos três fatores: a grande ocorrência de nevoeiros de radiação, a curta duração dos episódios dos nevoeiros orográficos e a baixa intensidade dos ventos na região (Arcova, 2013, Arcova et al., 2019).

<https://revistas.ufpr.br/revistaabclima/article/view/64388/39170>. $\quad$ Acesso em: $22 \quad$ out. 2019. doi:http://dx.doi.org/10.5380/abclima.v25i0.64388.

Ano 15 - Edição Especial - XIII Simpósio Brasileiro de Climatologia Geográfica - JUN 2019 

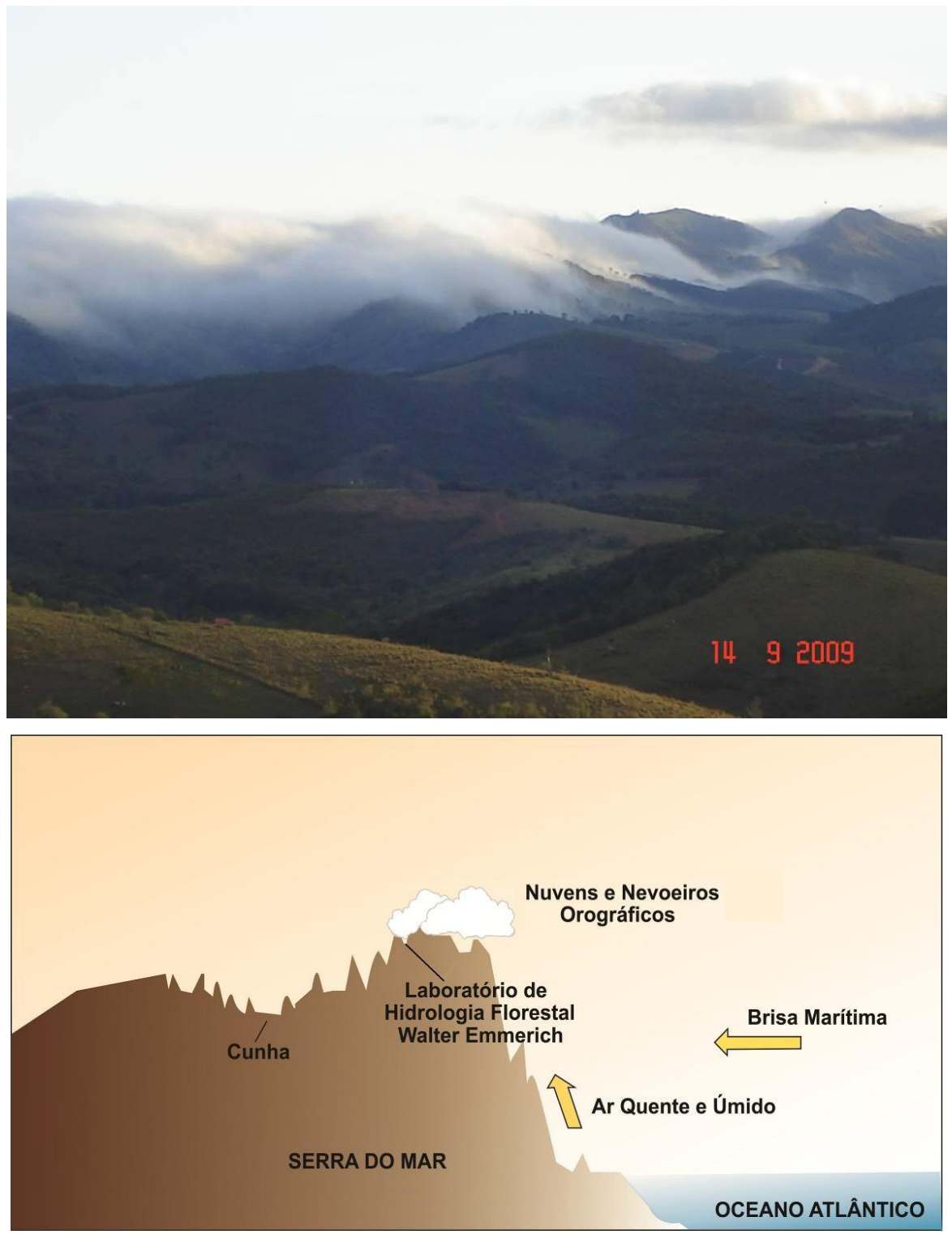

Figura 2 - Ocorrência de nevoeiro orográfico na região de Cunha, onde está localizada a área de estudo (Foto: Emerson Galvani, 14/09/2009, 17h00min). Visada da fotografia: leste/sudeste.

\subsection{A COLETA DE NEVOEIROS - PARTE 2}

Trata de projeto em andamento desenvolvido pela doutoranda Jakeline Baratto sob orientação do professor Cássio Arthur Wollmann vinculada ao Programa de Pós-Graduação em Geografia da Universidade Federal de Santa Maria - UFSM e da qual atuo como co-orientador. Os mesmos coletores de nevoeiro utilizados por Arcova em 2013 seguiram em uma longa viagem de aproximados 1.000 quilômetros até nova área de estudo.

A literatura indica que não existe um único instrumento que possibilita estudar todas as possíveis medições desejada ou necessária para as pesquisas 
sobre a quantificação da água dos nevoeiros. Existe uma ampla série de equipamentos, na sua maioria de fabricação artesanal. Os equipamentos são geralmente planos ou cilíndricos, com uma malha de polipropileno para a superfície de captação de água. Os dois modelos têm o mesmo funcionamento, sendo que a água que passar pela superfície coletora é retida e pelo processo de coalescência as gotículas formam gotas maiores e pela ação da gravidade drenam verticalmente (Bruijnzeel et. al., 2005).

Os coletores de nevoeiros possuem vantagens e desvantagens, a malha de polipropileno é o material mais empregado, pois é de fácil instalação no coletor, cuja estrutura do coletor também se torna mais simples e de baixo custo. Já os coletores que usam a superfície do tipo harpa requerem, normalmente, uma estrutura mais complexa para a passagem das linhas, o que torna a construção mais cara e também possui uma maior demanda de tempo (ARCOVA, 2013).

O coletor plano (figura 3) consiste em uma estrutura de ferro de área de captação de nevoeiro de $1 \mathrm{~m} \times 1 \mathrm{~m}$. Suas partes superior e inferior são construídas com barra cilíndrica maciça de 1/2 polegada de diâmetro e 1,30 m de comprimento, onde são soldadas barras roscadas de $5 / 16$ de polegada de diâmetro e um metro de comprimento. As laterais são confeccionadas em estrutura tubular de $2 \mathrm{~cm} \times 3 \mathrm{~cm}$ e $2,40 \mathrm{~m}$ de comprimento. Toda a estrutura é pintada com tinta antiferrugem e montada com parafusos, arruelas e porcas. Para evitar que a tensão dos fios que formam o painel coletor da água deforme a estrutura, duas barras de ferro são fixadas entre as barras superior e inferior do quadro. As ranhuras das barras roscadas são usadas para a passagem do fio de poliamida (linha de nylon) de $0,80 \mathrm{~mm}$ de espessura, formando um painel de duas camadas do tipo "harpa". A água de nevoeiro coletada é drenada para uma calha feita de chapa galvanizada de 0,50 mm de espessura, com $10 \mathrm{~cm}$ de largura x 1,06 m de comprimento, com altura das laterais de $7 \mathrm{~cm}$ e $35 \mathrm{~cm}$, proporcionando inclinação de $15^{\circ}$ ao fundo da mesma. Por intermédio de uma mangueira plástica ligada a um dreno na base da calha, a água é conduzida para um pluviômetro digital com precisão de 0,2 mm (Arcova, 2013).

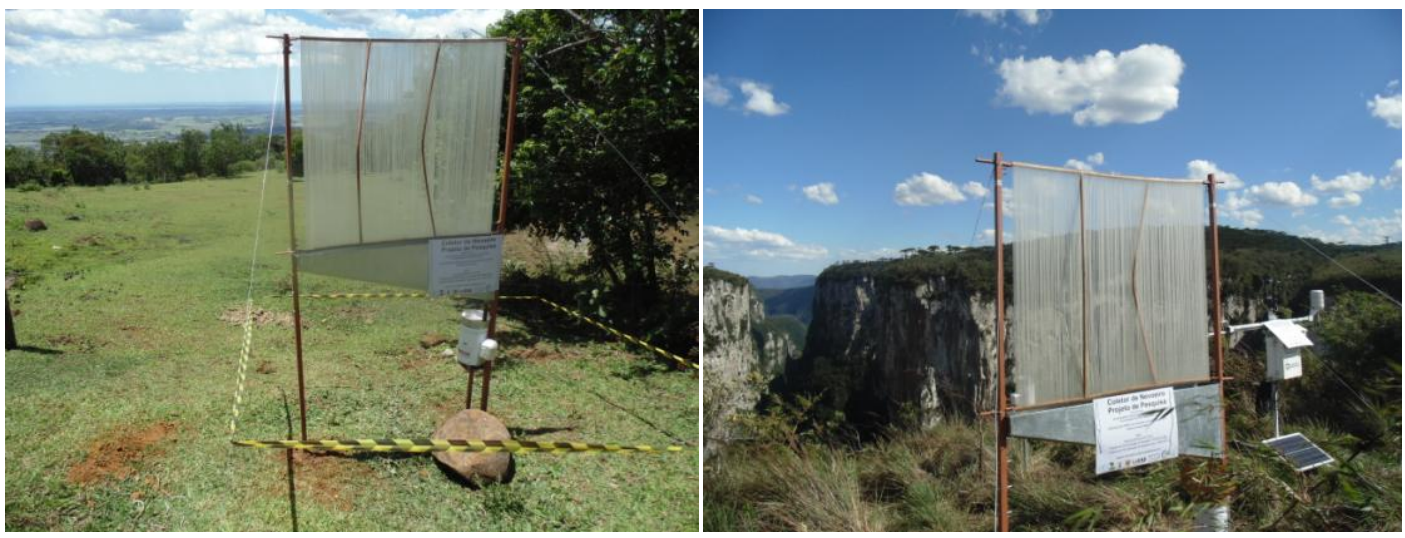

Figura 3 - Coletor de nevoeiro plano instalado no Parque Nacional Aparados da Serra, SC/RS: a esquerda coletar instalado na cota $490 \mathrm{~m}$ e a direita coletar instalado na cota 1.090 m ANMM. Ao fundo Estação Meteorológica Automática. Autoria: Jakeline Baratto, 2017. 

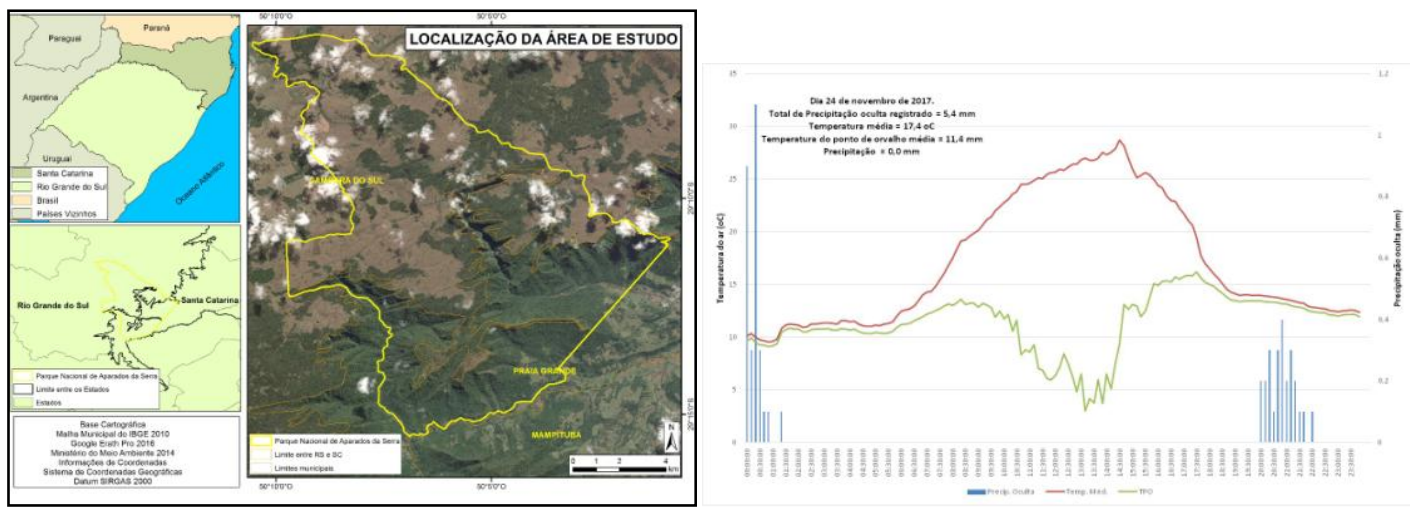

Figura 4 - O parque nacional de Aparados da Serra (coordenadas geográficas $29^{\circ} 15^{\prime} \mathrm{S}$ e $50^{\circ} 01^{\prime}$ W e $29^{\circ} 25^{\prime}$ S e $50^{\circ} 15^{\prime} \mathrm{W}$ ). Foi criado no ano de 59 pelo Decreto Estadual no 47.446, alterado em 17/03/1972 pelo Decreto Federal no 70.296. O parque possui uma área de 10.250 há (esquerda). Exemplo de dia de ocorrência com precipitação oculta (direita). Elaboração: Jakeline Baratto, 2017, 2019.

Patrício et al. (1998) destacam que em determinadas regiões os nevoeiros são mais frequentes, que em outras, e podem contribuir de modo significativo para a precipitação devido a condensação da umidade da atmosfera em contato com um obstáculo. Dessa forma, a precipitação oculta é um fenômeno decorrente da formação do nevoeiro, no entanto o nevoeiro precisa conter água líquida suficiente e que dure o tempo suficiente para que as gotas possam precipitar.

Para um projeto dessa envergadura algumas dúvidas metodológicas surgem, como por exemplo: - como identificar os eventos de nevoeiro apenas daqueles com nevoeiro e precipitação pluvial? Como separar os volumes oriundos da precipitação oculta daqueles da precipitação convencional? O ponto de orvalho seria um bom indicador de saturação do ar e consequentemente da ocorrência de nevoeiros? Qual o papel de controles climáticos como altitude, proximidade do oceano (maritimidade) e cobertura vegetal na produção e intensificação desses processos? São questões que a literatura nós deu caminhos e dicas, mas não uma solução cartesiana. Os resultados preliminares apontam que a precipitação oculta na área de estudo consiste em importante contribuição, em volume, para a disponibilidade hídrica regional e os dados dos pluviômetros convencionais podem estar subestimando esse volume.

\subsection{O MICROCLIMA DO MANGUEZAL}

Esse projeto é aquele que sem dúvida produziu os melhores resultados em termos de formação de recursos humanos, captação de recursos e publicações em periódicos qualificados, até o momento. A primeira fase desse projeto, que se iniciou em 2006 tendo como pressuposto um Trabalho de Graduação Individual (TGI, como definimos aqui em nossa IES), com apoio de edital Universal do CNPq, teve como proposta "avaliar a relação existente entre os controles (estrutura da vegetação, variação da maré e sistemas atmosféricos) e atributos climáticos (temperatura do ar, umidade absoluta do ar, radiação solar global, vento e precipitação) no ambiente manguezal localizado na Barra do Ribeira-Iguape/SP". Consistiu na essência da tese de Ano 15 - Edição Especial - XIII Simpósio Brasileiro de Climatologia Geográfica - JUN 2019 
Doutorado da pós-graduanda Nádia Gilma Beserra de Lima defendida em 2014 junto ao Programa de Pós-Graduação em Geografia Física da Universidade de São Paulo 5 .

Ousadia nossa montar uma torre micrometeorológica como $12 \mathrm{~m}$ de altura em pleno ambiente de manguezal, aliás, em uma ilha com ambiente mais instável ainda. Planejamento, boa vontade dos alunos, amigos e estagiários e alguma habilidade herdada dos tempos das lidas com a construção civil, foram úteis nesse momento. Uma espécie de balsa semifixa depositada no substrato lodoso composto de bambu gigante (Dendrocalamus giganteus) e alternados com vigas de madeira sobre a qual se assentou a base da torre de alumínio galvanizado. Tirantes e fixadores, distribuídos em três pontos da torre, em angulo de $120^{\circ}$ deram apoio lateral à estrutura. Não há texto descritivo que consiga demonstrar o desafio que foi essa etapa da pesquisa.

As interações que se processam a partir do recebimento da radiação solar resultam em ganhos e perdas de energia que condicionam as características térmicas dos ambientes. No caso da interação ocorrer com a presença de vegetação, essa energia é modificada/redistribuída até atingir a superfície do solo. As questões que se colocam são: existe interação entre os atributos (temperatura do ar, umidade do ar, radiação solar, vento e precipitação) e os controles climáticos (vegetação, variação da maré e sistemas atmosféricos) no manguezal, em escala microclimática? Como ocorre o acoplamento entre as escalas superiores e inferiores do clima e suas repercussões no manguezal? (Lima, 2014). Essa foi a hipótese perseguida nesse momento. Vamos às imagens.

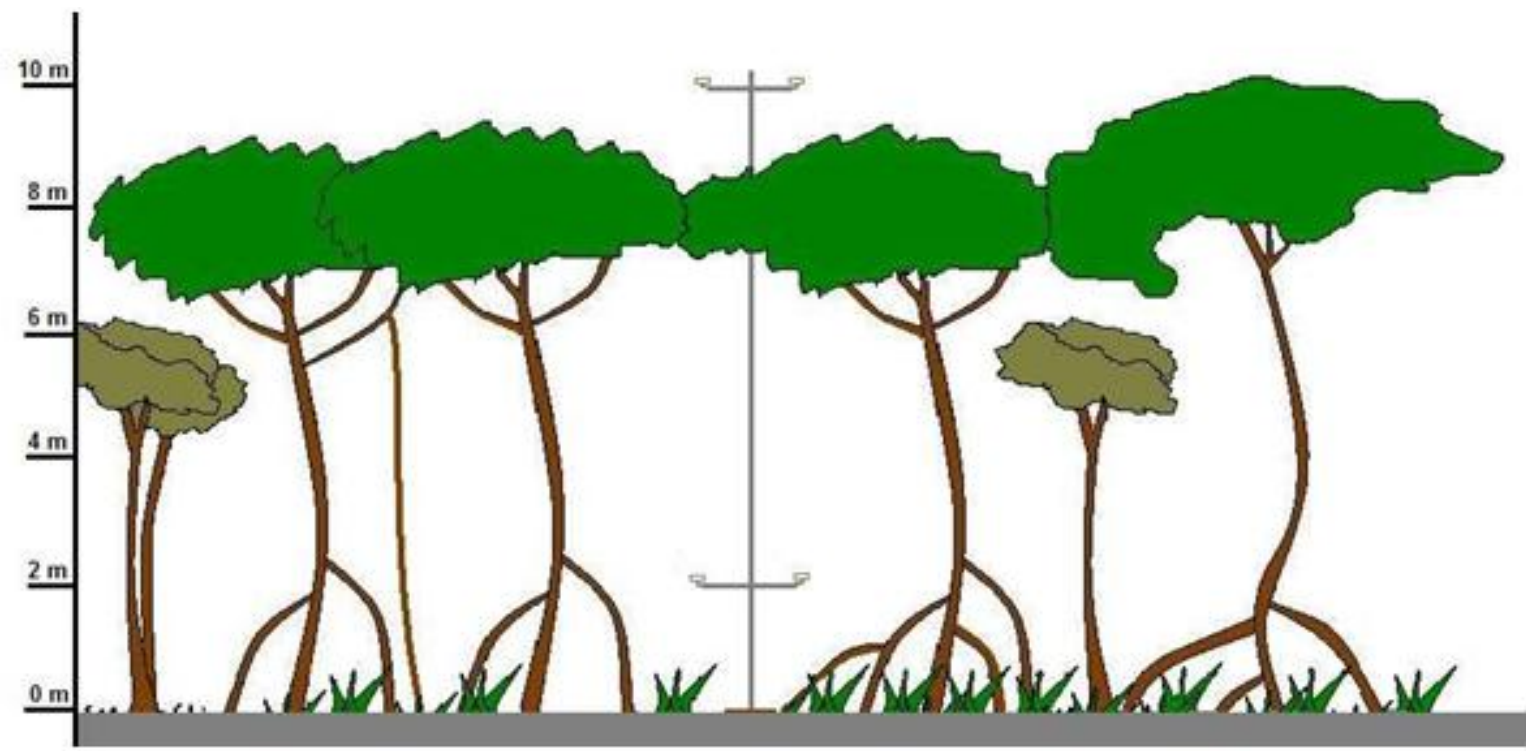

Figura 5 - Croqui de instalação da torre microclimática - Ilha dos Papagaios - Barra do Ribeira - Iguape/SP. Autoria: Nara Lima, 2009.

\footnotetext{
${ }^{5}$ Premiada durante o XI ENANPEGE com o prêmio "Aziz Nacib Ab'Sáber" de melhor tese com título "Interação dos atributos climáticos nos manguezais do Litoral Sul de São Paulo e sua relação com os controles climáticos" (Bolsista DR CNPq). 2014. Tese (Doutorado em Geografia (Geografia Física)) - Universidade de São Paulo, Conselho Nacional de Desenvolvimento Científico e Tecnológico. Orientador: Emerson Galvani.
} 


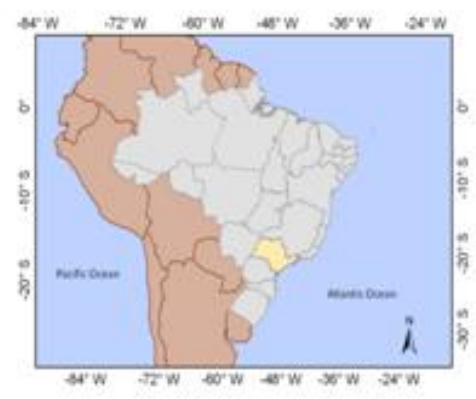

\section{Cananéia-Iguape Costal System}
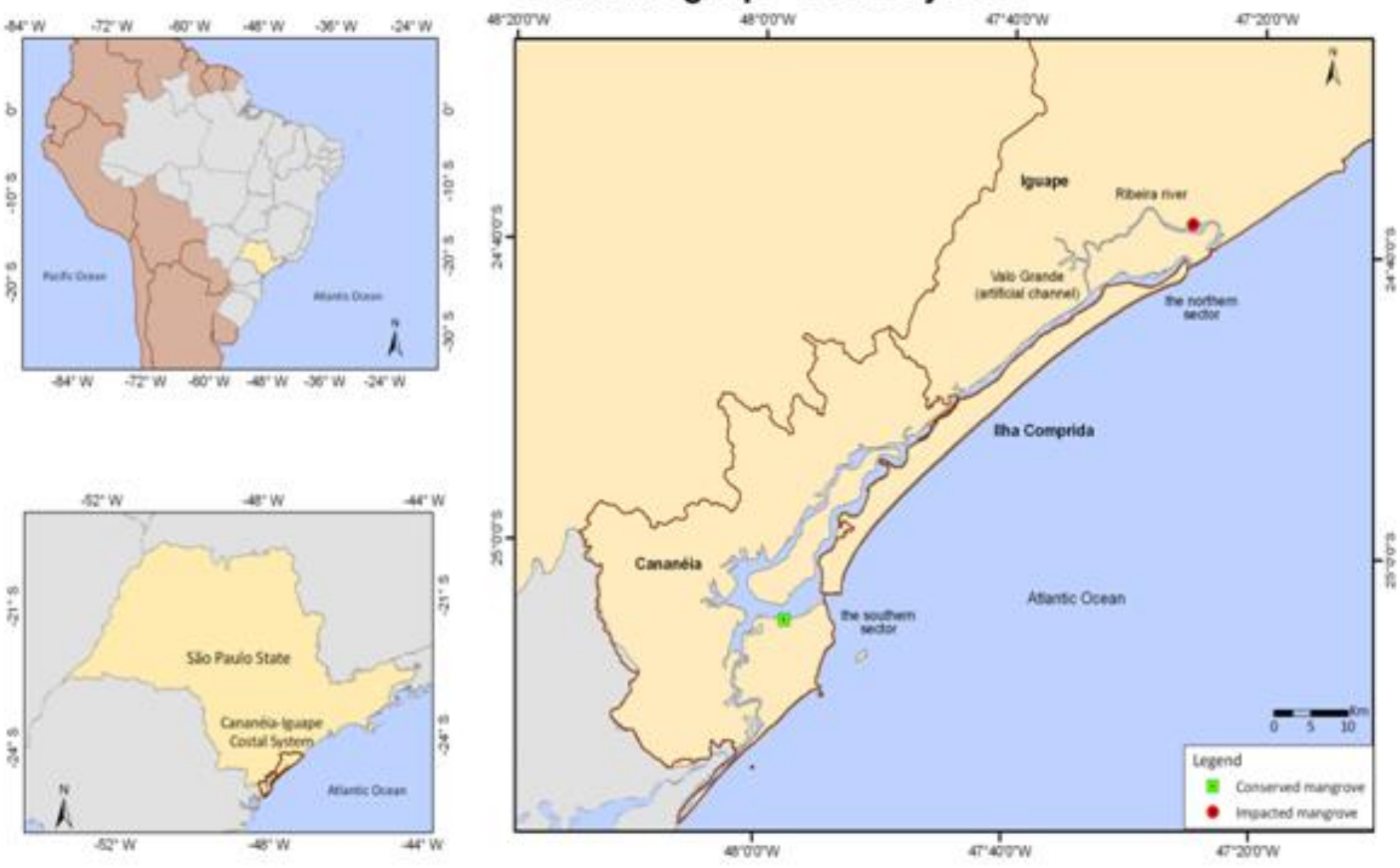

Figura 6 - Localização das duas estações meteorológicas - mangue conservado e mangue impactado - no contexto do Sistema Costeiro Cananéia-Iguape.
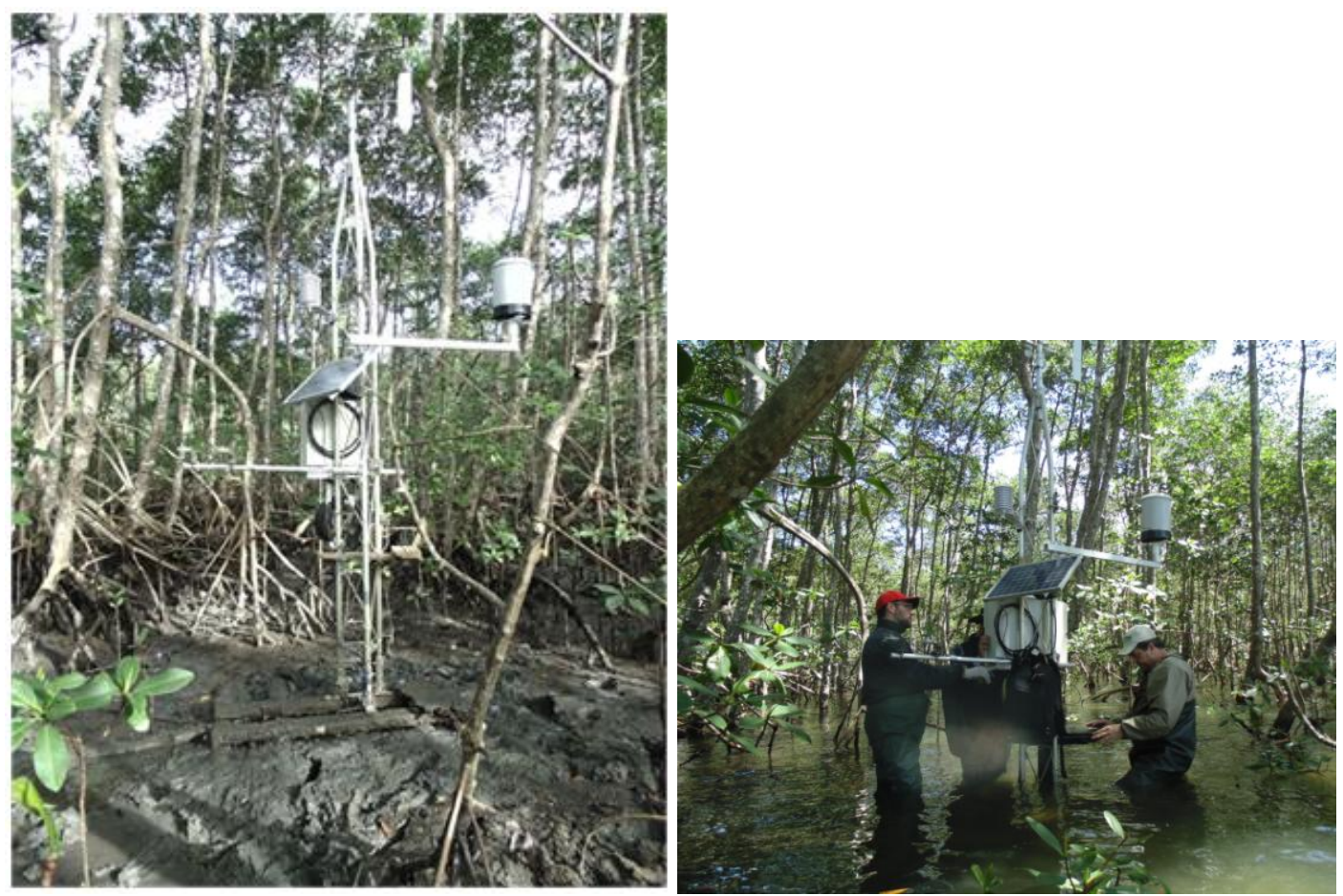

Figura 7 - Estação Meteorológica Automática instalada no ambiente de manguezal conservado no Parque Estadual Ilha do Cardoso - PEIC (Esquerda em condição de maré baixa e imagem a direita em condição de maré alta, Galvani, 2015 e 2017). 
No setor norte do sistema costeiro Canánéia-Iguape, na Barra do Ribeira, onde localiza-se parte da APACIP ${ }^{6}$, o levantamento microclimático foi iniciado em 2008, com a instalação de uma torre microclimática, contendo duas estações meteorológicas automáticas (EMA), de forma a efetuar análises da variação vertical dos atributos climáticos e da influência do dossel de manguezal no microclima. A torre microclimática apresenta uma estação meteorológica localizada a $2 \mathrm{~m}$ de altura em relação à superfície, contendo sensores de temperatura do ar, umidade relativa do ar, direção e velocidade do vento, precipitação e radiação solar global, visando obter os dados com a influência do dossel. A torre microclimática possui também outra estação meteorológica instalada de forma a ultrapassar o dossel da vegetação, com o intuito de registrar os atributos climáticos antes da interferência da vegetação, com $12 \mathrm{~m}$ de altura em relação a superfície, com obtenção dos mesmos atributos climáticos, além de um saldo-radiômetro, para obtenção do Saldo de Radiação no ambiente. Os equipamentos são programados para registro a cada 10 minutos.

No setor sul, onde se localiza o PEIC ${ }^{7}$, foi instalada uma EMA em 2011. A estação encontra-se a $2 \mathrm{~m}$ de altura do solo, contendo sensores de temperatura do ar, umidade relativa do ar, direção e velocidade do vento, radiação solar global e pluviosidade. A seguir são apresentadas as análises dos atributos climáticos monitorados nos bosques nas UCs de Uso Sustentável (APACIP) e de Proteção Integral (PEIC). No entorno, de ambas as EMAs foram instaladas parcelas permanentes nos bosques de mangue, onde é monitorada de estrutura vegetal e a ocorrência de vegetação associada, de acordo com metodologia proposta por Schaeffer-Novelli e Cintrón (1986).

A comparação dos ambientes considerados conservados localizados no PEIC e alterados na APACIP são trabalhados adotando as seguintes premissas:

- O clima regional em ambos os bosques de mangue (conservado e alterado) pode ser considerado uniforme dentro dos limites da área de estudo.

- A distância entre as Estações Meteorológicas Automáticas (EMAs) aproximados $70 \mathrm{~km}$ em um alinhamento NE-SW, não representam diferenças significativas nos atributos climáticos em uma escala climática de análise regional.

- A EMA instalada no manguezal alterado da APACIP, mesmo distante 4,3 $\mathrm{km}$ da linha de costa, não sobre influência, significativa dos efeitos de continentalidade.

- A EMA instalada no manguezal conservado do PEIC próximo a orla, contudo em condição sotavento da Ilha do Cardoso, também não apresenta efeito de sombra de chuva oriundas do relevo da área de estudo.

- Os resultados serão discutidos sempre considerando o manguezal conservado como referência.

Considera-se, portanto, que as diferenças encontradas nos atributos climáticos (temperatura do ar, umidade relativa do ar, precipitação, radiação solar global, direção e velocidade - media e rajada - dos ventos) são influenciados diferentemente pelo dossel da vegetação do mangue e

\footnotetext{
${ }^{6}$ APACIP é a Área de Proteção Ambiental de Cananéia-Iguapé-Peruíbe.

${ }^{7}$ PEIC é o Parque Estadual da Ilha do Cardoso.

Ano 15 - Edição Especial - XIII Simpósio Brasileiro de Climatologia Geográfica - JUN 2019
} 
consequentemente seu estado de conservação. A interação da radiação solar fluxos de entrada e saída de energia - são condicionados pelos aspectos estruturais do dossel do bosque de mangue em função de: área foliar, índice de área foliar, espécies, estrutura, dominância, abertura do dossel, entre outros aspectos fitossociológicos do manguezal. Resultados importantes desse projeto foram publicados em Beserra de Lima e Galvani (2013) e Lima e Galvani (2018).

No dia 30 de maio de 2019 um sistema meteorológico de forte intensidade produziu ventos intensos e ocorrência de granizo na região de Iguape e parte leste da bacia do Rio Ribeira de Iguape. A última rajada de vento registrada pelo anemômetro foi de $16,35 \mathrm{~m} / \mathrm{s}$ (equivalente a $58,86 \mathrm{~km} / \mathrm{h}$ as 08h30min) o que fato não representa um evento tão intenso. Nossa hipótese é que as conchas do anemômetro se romperam pelo impacto com o granizo antes mesmo de registrar o valor mais intenso do vento. As imagens ilustram bem a força do evento que resultou na morte de $100 \%$ das plantas de mague e tombamento da torre meteorológica (Figura 8). Os dados sinóticos, micrometerológicos e de estrututa da vegetação encontram-se em análise.

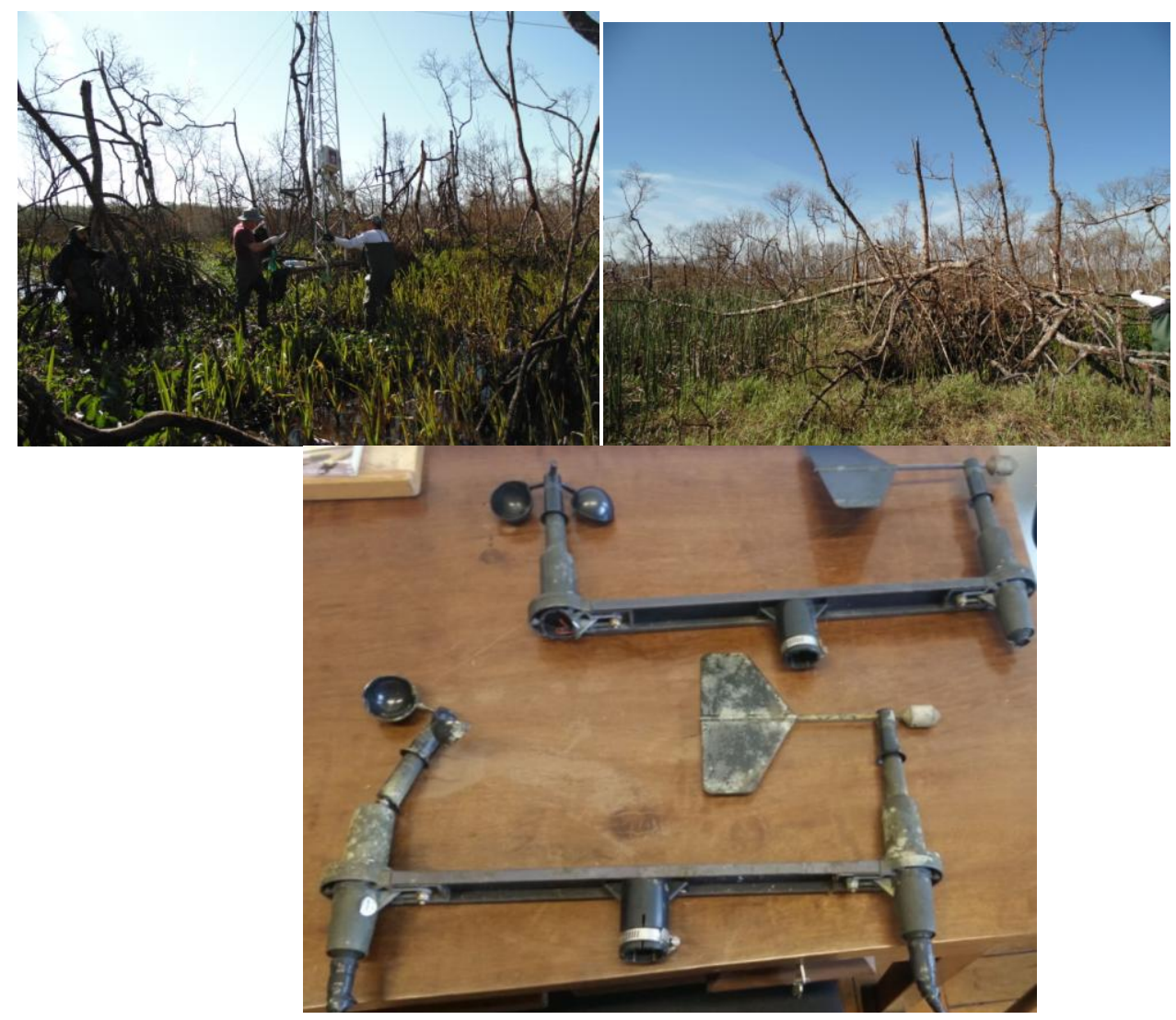

Figura 8 - Torre da estação meteorológica inclinada (esquerda) e detalhe da vegetação de manguezal (direita) após ocorrência de vento intenso e granizo de forte intensidade. $\mathrm{Na}$ imagem inferior detalhes dos danos causados aos anemômetros (Ilha dos Papagaios, Rio Ribeira de Iguape, Iguape, SP. Autoria: Galvani, 2019). 


\subsection{CONFORTO TÉRMICO E SENSAÇÃo TÉRMICA - MODELAGEM E PROPOSTA DO ÍNDICE DE CONFORTO SUBTROPICAL}

A proposta de realizar um estudo empírico propondo um índice de conforto térmico humano para a região sul baseado em levantamento de questionários a campo de fato foi outro enorme desafio. A proposta se consolidou com a tese de doutorado do, agora doutor, João Paulo Assis Gobo intitulada "Bioclimatologia subtropical e modelização do conforto humano: da escala local à regional" defendida em 2018 no PPG em Geografia Física da Universidade de São Paulo. "O objetivo desta pesquisa consistiu em avaliar e propor índices de conforto térmico humano por meio de variáveis ambientais, subjetivas e individuais, em escala climática local e regional. Para tanto, partese da hipótese de que o estudo abrangente do conforto térmico humano em escala local, por meio de entrevistas e análise do tempo in-loco, forneceria subsídios para o desenvolvimento de um índice que transite até a escala regional do clima. Parte-se, então, de um método indutivo experimental (levantamento em campo de variáveis climáticas, individuais e subjetivas) onde foram feitas coletas em campo no período de agosto de 2015, janeiro e julho de 2016, com a aplicação de questionários à população simultâneos a coleta de dados meteorológicos" (Gobo, 2018, p.11)

Deslocou-se equipe e equipamentos para o interior do Rio Grande do Sul, particularmente a localidade de Santa Maria. A escolha desse local fundamentase na literatura que considera sua posição estratégica nos estudos de clima do estado por situar-se em posição central (Depressão Rio-grandense) e submetida a todos os tipos de tempo e padrões de circulação atmosférica que acometem essa região (SARTORI, 1979; 1993).

Sem recursos financeiros, contando apenas com uma estação meteorológica automática frankenstaneada de sobras de sensores e equipamentos recuperados de projetos anteriores e com uma equipe de voluntários seguiu para a área de estudo. As condições sinóticas também eram limitador nesse processo, pois o inverno e verão - duas estações de amostragem - deveriam ser típicos do clima regional, mas não o foram. Fato que resultou da necessidade de repetir o experimento de inverno, pois o inverno de 2015 apresentou temperaturas atípicas para essa latitude e época do ano.

Durante a análise de agosto de 2015 foram entrevistadas 6 pessoas a cada 10 minutos (em conformidade com o período de registro dos dados meteorológicos pela estação), totalizando 36 pessoas entrevistadas a cada hora, 288 pessoas entrevistadas nas 8 horas de coleta de dados para cada dia e 864 pessoas entrevistadas ao final dos três dias de trabalho de campo. $\mathrm{Na}$ análise seguinte, em janeiro de 2016, foram entrevistadas 6 pessoas a cada 20 minutos, totalizando 18 pessoas a cada hora, 144 pessoas entrevistadas nas 8 horas de coleta de dados e 432 pessoas entrevistadas ao final dos 3 dias de coleta. Por fim, na última análise, de julho de 2016, foram adotados os mesmos procedimentos da coleta de janeiro, totalizando 432 entrevistas ao final dos 3 dias de trabalho de campo (Gobo, 2018). Vamos as imagens.

\footnotetext{
${ }^{8}$ Disponível em: http://www.teses.usp.br/teses/disponiveis/8/8135/tde-23022018-094537/pt-br.php Ano 15 - Edição Especial - XIII Simpósio Brasileiro de Climatologia Geográfica - JUN 2019
} 


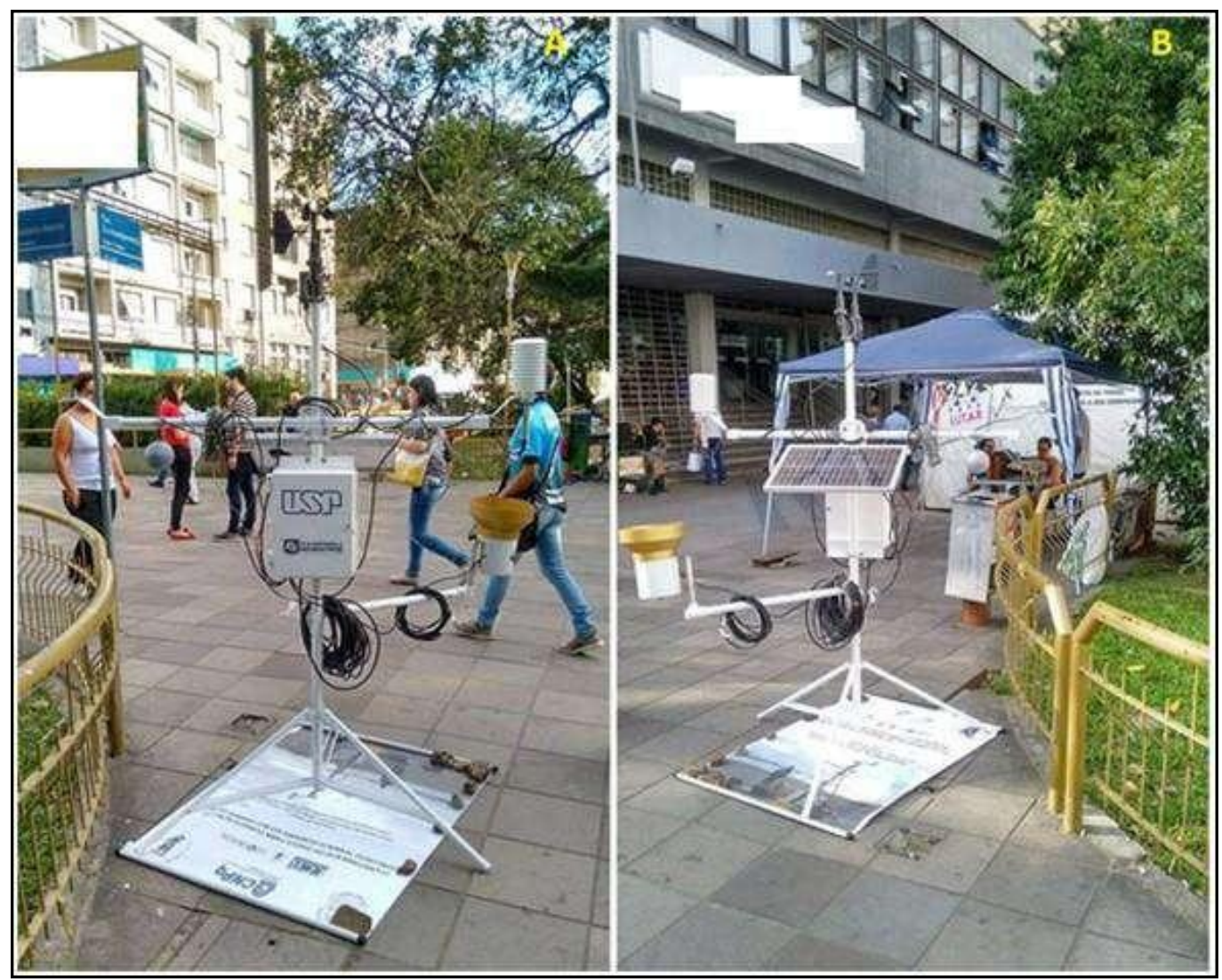

Figura 9 - Estação meteorológica automática instalada em praça central em Santa Maria - RS.

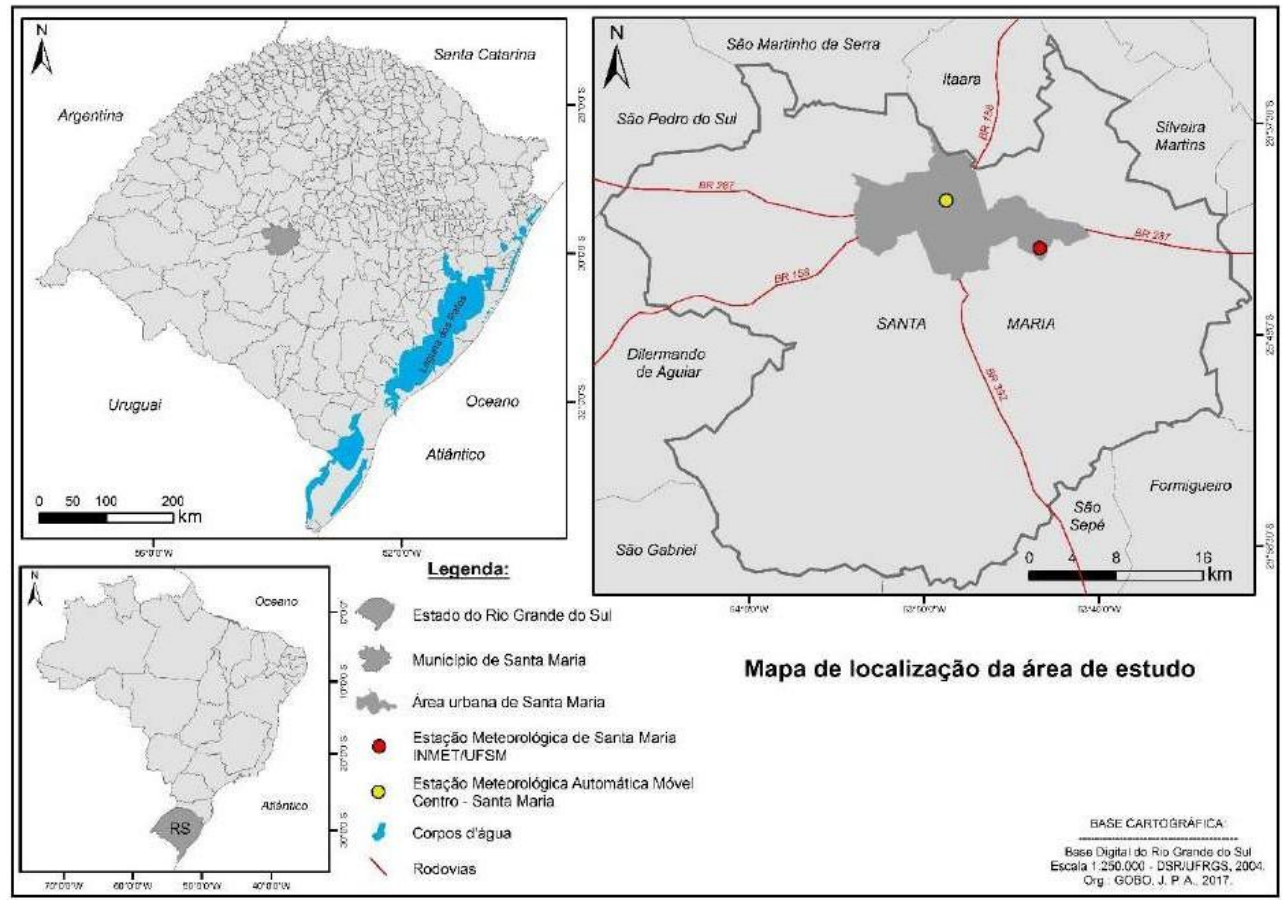

Figura 10 - Localização da área de estudo - área urbana de Santa Maria, RS. Ano 15 - Edição Especial - XIII Simpósio Brasileiro de Climatologia Geográfica - JUN 2019 
De fato essa tese produziu importantes artigos que foram publicados em períodicos nacionais e internacionais com destaque para: Gobo et al. (2018) e Gobo et al. (2019). Essa proposta de análise com indices de conforto prossegue em parceria com pesquisadores do Instituto Astronômico e Geofísico (IAG/USP), da Faculdade de Arquitetura e Urbanismo (FAU/USP), da Universidade Estadual Paulista (UNESP/Presidente Prudente) e da Universidade de Rondônia (UNIR) onde o Dr. Gobo atua como docente.

Há sem dúvida outros projetos que serviram-se da produção de dados primários para compor seus resultados dentre eles: Estudo microclimático do ambiente de cavernas, Parque Estadual Intervales, SP, defendido pela Bárbara Nazaré da Rocha em seu mestrado junto ao Programa de Pós-Graduação em Geografia Física; a dissertação e a tese de Doutorado de Marcos Alexandre Milanesi que estudou o efeito orográfico e as unidades climáticas na Ilha de São Sebastião, Ilha Bela, SP, assim como, os trabalhos de Gustavo Armani que realizou análises topo e microclimática tridimensional em uma microbacia hidrográfica de clima tropical úmido de altitude na região do Parque Estadual da Serra do Mar em Cunha, SP. Não há espaço aqui para detalhar as técnicas, os desafios e os aprendizados obtidos em cada um desses projetos.

\section{CONSIDERAÇÕES FINAIS}

Esse relato histórico das alternativas que nos servimos nos últimos tempos para produzir dados primários em pesquisas climáticas nos faz refletir: 1) é possível pensar em estratégias, metodologicamente, adequadas para monitorar os atributos do clima e responder às perguntas de seu projeto de pesquisa onde não há dados na escala temporal e espacial que lhe atenda; 2) a falta de recursos financeiros e humanos pode ser contornada com criatividade e parcerias dentro do grupo de pesquisa onde todos ajudam todos; 3) o mais importante é conhecer seu objeto de pesquisa por meio de pesquisa bibliográfica e leitura sobre o tema e, ter muito claro quais são as questões a serem respondidas com o instrumental que está levando à campo. Caso contrário, será um esforço físico, mental e financeiro enorme que poderia ter sido respondido com dados secundários.

\section{REFERÊNCIAS BIBLIOGRÁFICAS}

ARCOVA, Francisco Carlos Soriano. Avaliação do potencial hidrológico dos nevoeiros e da precipitação oculta em ambiente de Floresta Ombrófila Densa Montana na Serra do Mar, Cunha, SP. 2013. Tese (Doutorado em Geografia Física) - Faculdade de Filosofia, Letras e Ciências Humanas, Universidade de São Paulo, São Paulo, 2013. doi:10.11606/T.8.2013.tde-03022014-115048. Acesso em: 2019-06-15.

ARCOVA, Francisco Carlos Soriano et al. OCORRÊNCIA DE NEVOEIROS EM UMA MICROBACIA EXPERIMENTAL NA SERRA DO MAR, CUNHA, SP). Revista Brasileira de Climatologia, [S.I.], v. 18, out. 2016. ISSN 2237-8642. Disponível em: <https://revistas.ufpr.br/revistaabclima/article/view/44956>. Acesso em: 22 out. 2019. doi:http://dx.doi.org/10.5380/abclima.v18i0.44956.

ARCOVA, Francisco Carlos Soriano et al. AVALIAÇÃO DA PRECIPITAÇÃO OCULTA NA SERRA DO MAR COM COLETORES PASSIVOS DE NEVOEIRO. Revista 
Brasileira de Climatologia, [S.I.], v. 25, ago. 2019. ISSN 2237-8642. Disponível em: <https://revistas.ufpr.br/revistaabclima/article/view/64388/39170>. Acesso em: 22 out. 2019. doi:http://dx.doi.org/10.5380/abclima.v25i0.64388.

BRUIJNZEEL, L. A.; EUGSTER, W.; BURKARD, R. Fog as hydrologic input. In: ANDERSON, M. G. (Ed.). Encyclopedia of hydrological sciences. New Jersey: John Wiley \& Sons, 2005. cap. 38, p. 559-582.

GOBO, João Paulo Assis. Bioclimatologia subtropical e modelização do conforto humano: da escala local à regional. 2017. Tese (Doutorado em Geografia Física) - Faculdade de Filosofia, Letras e Ciências Humanas, Universidade de São Paulo, São Paulo, 2017. Disponível em: <http://www.teses.usp.br/teses/disponiveis/8/8135/tde-23022018-094537/>. Acesso em: 2019-06-26.

GOBO, J.P.A.; GALVANI, E.; WOLLMANN, C.A. Subjective Human Perception of Open Urban Spaces in the Brazilian Subtropical Climate: A First Approach. Climate, 2018, 6, 24. DOI: https://doi.org/10.3390/cli6020024

GOBO, J.P.A.; FARIA, M.R.; GALVANI, E.; AMORIM, M.C.C.T.; CELUPPI, M.C.; WOLLMANN, C.A. Empirical Model of Thermal Comfort for Medium-Sized Cities in Subtropical Climate. Atmosphere, 2019, 10, 576. DOI: https://doi.org/10.3390/atmos10100576

LIMA, Nádia Gilma Beserra de. Interação dos atributos climáticos nos manguezais do litoral sul de São Paulo e sua relação com os controles climáticos. 2014. Tese (Doutorado em Geografia Física) - Faculdade de Filosofia, Letras e Ciências Humanas, Universidade de São Paulo, São Paulo, 2014. doi:10.11606/T.8.2014.tde-08052015-125807. Acesso em: 2018-06-26.

BESERRA DE LIMA, NÁDIA GILMA; GALVANI, EMERSON . Mangrove Microclimate: A Case Study from Southeastern Brazil. Earth Interactions, v. 17, 2013, URL: https://journals.ametsoc.org/doi/citedby/10.1175/2012EI000464.1, DOI: https://doi.org/10.1175/2012EI000464.1

LIMA, Nádia Gilma Beserra de, GALVANI, Emerson. Interação dos atributos climáticos nos manguezais do litoral sul de São Paulo e sua relação com os controles climáticos. Confins. v.36, 2018, URL: http://journals.openedition.org/confins/14724; DOI: 10.4000/confins. 14724.

RIBEIRO, Antonio Giacomini. As escalas do clima. Boletim de Geografia Teorética, 23(46), p.288-294, 1993.

PATRÍCIO, Maria do Sameiro; Gonçalves, Ana Cristina; David, Jorge Soares (1998) - Intercepção horizontal do nevoeiro pela vegetação. Silva Lusitana. ISSN 0870-6352. 6:2, p.247-256. Disponivel em: <https://bibliotecadigital.ipb.pt/handle/10198/3888>. Acesso em: 25 de junho 2018..

PEDELABORDE, Pierre. Introduction à l'étude scientifique du climat. Notions élémentaires de climatologie dynamique. Paris: Centre de Documentation Universitaire, 1959. 150p.

SARTORI, M. G. B. O Clima de Santa Maria: do regional ao urbano. Dissertação (Mestrado em Geografia) - Faculdade de Filosofia, Letras e Ciências Humanas, USP, São Paulo, 1979. 
SARTORI, M. G. B. A circulação atmosférica regional e os principais tipos de sucessão do tempo no inverno do Rio Grande do Sul, Brasil. Ciência e Natura, 15, p.69-93, 1993 